\section{Oral clonidine reduces postoperative PCA morphine requirements}

Joseph Park MD CCFP FRCPC, Jay Forrest MD PhD FRCPC, Rick Kolesar MD FRCPC, Dolly Bhola MD FRCPC, Scott Beattie MD PhD FRCPC, Chris Chu MD
Purpose: The purpose of this study was to evaluate the effect of perioperative oral clonidine on postoperative analgesia and PCA morphine requirements in adult patients after major orthopaedic knee surgery.

Methods: In this prospective, double blind, placebo-controlled study 44 patients undergoing either total knee replacement or hemiarthroplasty of the knee were randomly assigned to receive oral placebo or clonidine $\left(5 \mu \mathrm{g} \cdot \mathrm{kg}^{-1}\right) 1.5 \mathrm{hr}$ before surgery, and at $12 \mathrm{hr}$, and $24 \mathrm{hr}$ after the initial dose. Five patients were subsequently withdrawn from study. No other preoperative drugs were given. Preoperative sedation score was recorded. A standardized general anaesthetic was administered to all patients. Postoperative blood pressure, heart rate, PCA morphine use, visual analogue score (VAS) for pain, sedation, nausea, and pruritus were recorded for $36 \mathrm{hr}$ postoperatively.

Results: The cumulative PCA morphine used was 37\% lower after clonidine $57.3 \pm 26.8 \mathrm{mg}$ (mean $\pm S D$ ) compared with placebo $91 \pm 31.6 \mathrm{mg}(P=0.031)$. There was no difference in pain or sedation scores postoperatively but patients who received clonidine were more sedated preoperatively $(P<$ 0.001 ) and had a lower mean arterial blood pressure throughout the period of study by 10 to $26 \mathrm{mmHg}(P<0.0001)$. Clonidine reduced the incidence of postoperative nausea $(25 \%$

\section{Key words}

ANALGESICS: morphine;

PAIN: postoperative;

SYMPATHETIC NERVOUS SYSTEM: phamacology, clonidine.

From the Department of Anaesthesia, McMaster University, Hamilton, Ontario.

Presented at the Annual Meeting of the Canadian Anaesthetists' Society, Ottawa, June 1995. Supported by grants from the PSI Foundation, and the Regional Medical Associates Scholarship Fund at McMaster University Faculty of Health Sciences.

Address correspondence to: Dr. Joseph Park, Department of Anaesthesia, McMaster University Medical Centre, HSC2U4, 1200 Main St. W., Hamilton, Ontario, L8N 3Z5.

Accepted for publication 11th April, 1996. vs $74 \%)(P<0.01)$ and vomiting compared with placebo $(10 \%$ vs $53 \%)(P<0.01)$ and required less antiemetic (dimenhydrinate $37.5 \pm 20.9 \mathrm{mg} v \mathrm{~s} 82.1 \pm 49.4 \mathrm{mg}$ ) but not statistically significant $(P=0.065)$.

Conclusions: Oral clonidine is a useful component to postoperative balanced analgesia as it decreases PCA morphine requirements and decreases the incidence of nausea and vomiting.

Objectif: Cette étude visait à évaluer chez des adultes l'influence de la clonidine orale périopératoire sur l'analgésie postopératoire et les besoins de morphine après une chirurgie orthopédique majeure du genou.

Méthodes: Pour cette étude prospective, à double aveugle et contrôlée avec placebo, 44 patients opérés pour remplacement total ou hémiarthroplastie du genou étaient répartis pour recevoir soit un placebo soit de la clonidine $\left(5 \mu \mathrm{g} \cdot \mathrm{kg}^{-1}\right)$ per os $1,5 \mathrm{~h}$ avant la chirurgie, et à la $12^{e} \mathrm{~h}$ et à la $24^{e} \mathrm{~h}$ après la dose initiale. Par la suite, cinq patients étaient exclus de l'étude. Aucun autre médicament préopératoire n'était administré. Les scores de sédation préopératoire étaient enregistrés. Une anesthésie générale normalisée était administrée à tous les patients. En postopératoire, la pression artérielle, la fréquence cardiaque, l'utilisation de la morphine en PCA, le score sur échelle visuelle analogique (EVA) de la douleur, la sédation, la nausée et le prurit étaient enregistrés pendant les 36 première heures postopératoires.

Résultats: Après la clonidine, la dose cumulative de morphine de 57,3 $\pm 26,8 \mathrm{mg}$ (moyenne \pm ET) en PCA, était de $37 \%$ inférieure à la dose après placebo de $91 \pm 31,6 \mathrm{mg}(P=$ $0,031)$. Il n'y avait aucune différence au regard des scores de douleur et de sédation, mais la sédation était plus profonde en préoperatoire chez les patients sous clonidine $(P<0,001)$ et ces derniers avaient une pression artérielle inférieure de 10 à $26 \mathrm{mmHg}$ pendant l'étude $(P<0,0001)$. La clonidine diminuait l'incidence des nausées ( $25 \%$ vs $74 \% ; P<0,01)$ et des vomissements ( $10 \%$ vs 53\%; $P<0,05$ ) postopératoires comparativement au placebo et nécessitait moins d'antiémétique (dimenhydrinate $37,5 \pm 20,9 \mathrm{mg}$ vs $82,1 \pm 49,4 \mathrm{mg}$ ) mais de façon non significative $(P=0,065)$.

Conclusion: En diminuant les besoins de morphine en PCA et en réduisant l'incidence des nausées et des vomissements, la clonidine orale constitue en composante efficace de l'analgésie postopératoire équilibrée. 
Clonidine is a centrally acting alpha ${ }_{2}$ adrenergic agonist that was introduced more than two decades ago as an antihypertensive agent. However its usefulness at antihypertensive doses was limited because of marked sedation. Clinical studies have shown that clonidine decreases anaesthetic requirements during surgery ${ }^{1-3}$ and increases postoperative analgesia ${ }^{4-7}$ There are only two studies in which oral clonidine was used to evaluate the effect on the postoperative analgesia ${ }^{8,9}$ although sympathetic mechanisms in postoperative pain are well recognized. ${ }^{12}$ However the results were inconsistent and the side-effects of clonidine were inadequately documented. Clonidine is rapidly and almost completely absorbed after oral administration with a time to maximum plasma concentration of between 1.5 and $2 \mathrm{hr}$ and elimination half-life of 8 to $12 \mathrm{hr} .{ }^{10,11}$

This prospective, randomized, placebo-controlled study evaluates the effect of preoperative and postoperative oral clonidine on postoperative PCA morphine requirements in patients having major orthopaedic knee surgery.

\section{Methods}

This study was approved by the institutional ethics committee at McMaster University. All patients provided informed consent to participate in the study. Included were adult patients over $50 \mathrm{yr}$ of age, ASA physical status 1 to 3 , scheduled for total knee replacement or hemiarthroplasty of knee under general anaesthesia. Exclusion criteria were: known allergy to clonidine or to morphine; patients concomitantly taking clonidine, methyldopa, benzodiazepines, tricyclic antidepressants, or beta blocking drugs; patients with aortic stenosis, atrio-ventricular conduction block, sinus bradycardia, renal failure or hepatic dysfunction; patients scheduled to have surgery under regional with or without general anaesthesia; patients unable to understand or use PCA pain control.

At least one week before surgery patients eligible for the study were seen in the preoperative assessment clinic when the VAS scales for pain, sedation, nausea, and pruritus; and the use of PCA pump were explained. Informed consent was obtained during this preoperative assessment visit. Each patient was randomly assigned by the hospital pharmacy using equal allocation to receive either oral placebo or oral clonidine $\left(5 \mu \mathrm{g} \cdot \mathrm{kg}^{-1}\right)$ administered as identical capsules. A dose of $5 \mu \mathrm{g} \cdot \mathrm{kg}^{-1}$ was used as this was recommended and commonly used in the previous studies. ${ }^{8,11}$ Study medications were administered one and a half hours before surgery, $12 \mathrm{hr}$ and $24 \mathrm{hr}$ after the initial dose. No other preoperative medications were given. Just before induction of anaesthesia the VAS sedation score was recorded.

\section{Anaesthesia and PCA morphine}

A standard protocol for general anaesthesia was used: induction included fentanyl up to $5 \mu \mathrm{g} \cdot \mathrm{kg}^{-1}$, vecuronium $0.1 \mathrm{mg} \cdot \mathrm{kg}^{-1}$ sodium thiopentone up to $5 \mathrm{mg} \cdot \mathrm{kg}^{-1}$ to titrate to loss of response to command, all patients had tracheal intubation; anaesthesia was maintained with nitrous oxide and oxygen (2:1), fentanyl $2-3 \mu \mathrm{g} \cdot \mathrm{kg} \cdot \mathrm{hr}^{-1}$, vecuronium $1-3 \mathrm{mg}$ as required for muscle relaxation, isoflurane to maintain the systolic blood pressure within $\pm 30 \%$ of the preoperative value. At the end of surgery and after tracheal extubation patients were transferred to the post-anaesthesia care unit (PACU) where PCA morphine was started. Priming doses of PCA intravenous morphine $(2.5 \mathrm{mg}$ every five minutes to a maximum of $30 \mathrm{mg}$ ) were administered until adequate analgesia was obtained. Subsequently the PCA settings were: bolus dose $=1-2 \mathrm{mg}$, lockout interval $=10 \mathrm{~min}$, no maximum limit.

\section{Measurements}

The following assessments were made:

1 Preoperative VAS sedation (minimum $0=$ completely alert to maximum $100=$ extremely drowsy).

2 Supine BP, HR during the preoperative visit preinduction, one minute before and one minute and three minutes after tracheal intubation, one hour after induction, on admission to the PACU, then every eight hours for $36 \mathrm{hr}$.

3 VAS pain(minimum $0=$ no pain to maximum $100=$ worst pain), sedation, nausea (minimum $0=$ no nausea to maximum $100=$ worst nausea), pruritus (minimum $0=$ no pruritus to maximum $100=$ worst pruritus) scores every four hours for $36 \mathrm{hr}$. (Nausea was defined as an outcome if VAS nausea score was $\geq 25$ )

4 The dose of morphine used, attempted uses, and cumulative dose administered by PCA pump (Abbott Life Care $3000^{\circledR}$ or Graseby 3300 ).

5 Patients who vomited and the amount of anti-emetic (dimenhydrinate, or prochlorperazine) if required were noted. The dose of anti-pruritic (diphenhydramine) if required was noted. The use of postoperative oxygen, time to ambulation, length of hospital admission were also recorded.

Patients were withdrawn from the study if marked hypotension $(<90 \mathrm{mmHg}$ systolic) or bradycardia ( $<45$ $\mathrm{b} \cdot \mathrm{min}^{-1}$ ) occurred and was unresponsive to intravenous fluids and ephedrine. Any patient who became very sedated and who did not respond to a single dose of intravenous naloxone $(0.4 \mathrm{mg})$ was also withdrawn from the study.

Statistical analysis

Results were summarized as means and standard devia- 
TABLE Patient demographic data

\begin{tabular}{lcc}
\hline & Clonidine & Placebo \\
\hline$n$ & 20 & 19 \\
Age* & $67(6.50)$ & $68(7.9)$ \\
Sex (M/F) & $9 / 11$ & $7 / 12$ \\
Weight (kg)* & $88.7(14.5)$ & $81.7(12.5)$ \\
ASA Physical status & 2 & 2 \\
Surgical duration (min)* $^{*}$ & $154(28)$ & $154(35)$ \\
\hline
\end{tabular}

*Mean (SD).

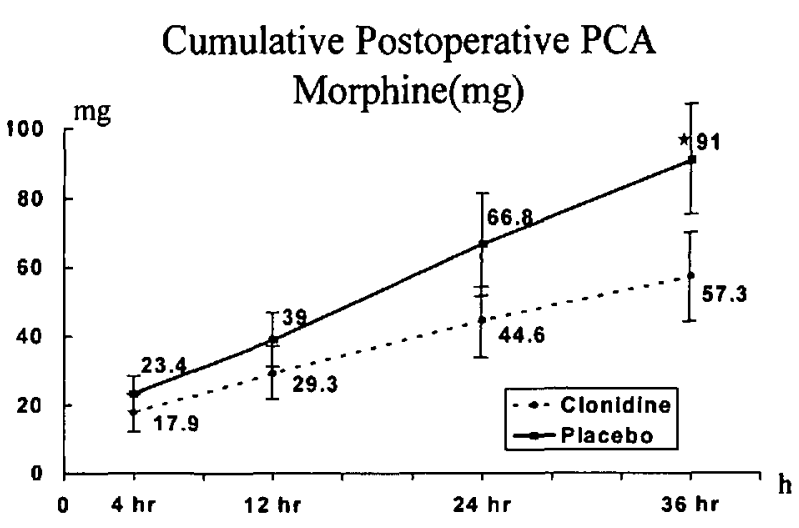

FIGURE 1 Cumulative morphine use in the clonidine group $(n=20)$ and in the placebo group $(n=19)$ at $4 \mathrm{hr}, 12 \mathrm{hr}, 24 \mathrm{hr}, 36 \mathrm{hr}$ postoperatively. Results are expressed as mean and SD. $P=0.031 . P$ values for group effect $=0.031$, time effect $<0.0001$, interaction between group.time effect $<0.0001$.

tion and tabulated for clonidine and placebo groups. BMDP 5V V.71, 1993 was used to do statistical analysis. Parametric data were analyzed with repeated measures analysis of variance (ANOVA) and by unpaired Student's $t$ test. Non-parametric data were analyzed by Chi square with Yates' correction. A $P$ value $\leq 0.05$ was considered statistically significant. The sample size was calculated based on the expected reduction in postoperative morphine requirement (estimated difference $=0.35$ ) which we estimated from the preliminary data on 11 patients, the variance of morphine use after total knee arthroplasty, alpha $=0.05$, and power $=0.85$. The calculated sample size was estimated to be 22 per group.

\section{Results}

Forty-four patients were enrolled in the study. Five patients were withdrawn (three in the placebo group and two in the clonidine group): in two patients surgery was cancelled, in one patient a different surgical procedure was performed, in one patient regional anaesthesia was used, and one patient was too drowsy to take the assigned study medication (placebo). Thirty-nine pa-

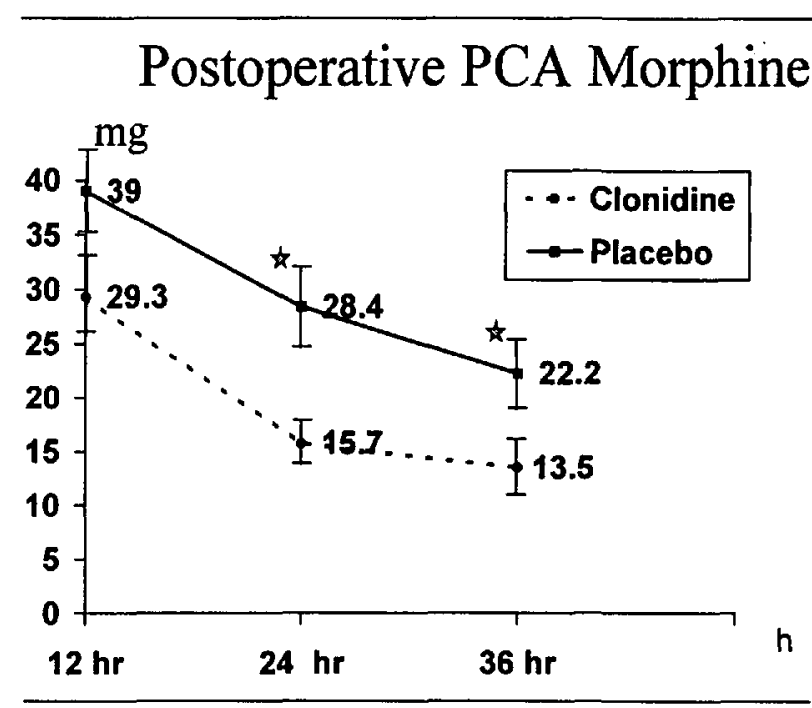

FIGURE 2 Postoperative morphine requirements for each $12 \mathrm{hr}$ period in both groups. Results are expressed as mean and SD. $P<<$ 0.05 .

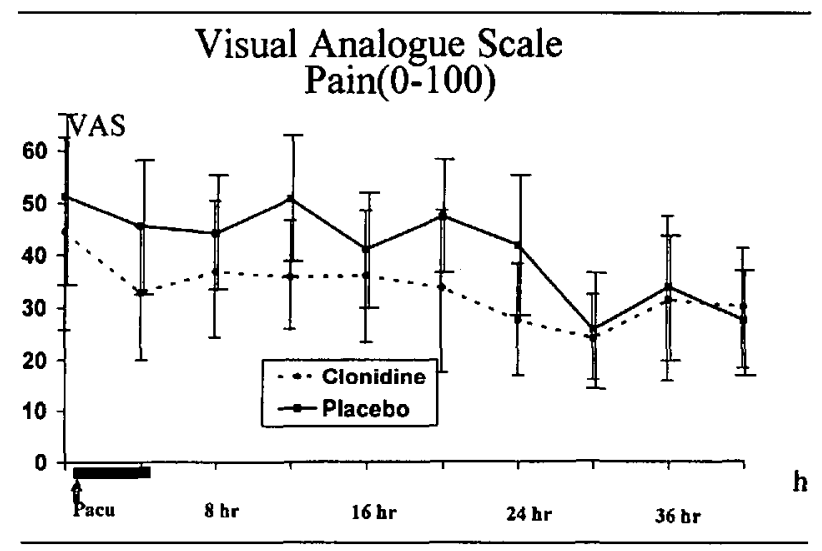

FIGURE 3 VAS for pain in both groups every four hours postoperatively for 36 hr. Results are expressed as mean and SD.

tients were analyzed ( 20 in the clonidine group and 19 in the placebo group).

There was no difference between the clonidine and placebo groups for age, sex, weight, ASA physical status, or surgical duration (Table). The cumulative dose of PCA morphine was $37 \%$ less in the clonidine group $(57.3 \pm 26.8 \mathrm{mg})$ than in the placebo group $(91 \pm 31.6$ $\mathrm{mg}$ ) after $36 \mathrm{hr}(P=0.031)$ (Figure 1). However, the mean morphine dose was lower after clonidine than after placebo in each of the $12 \mathrm{hr}$ periods of study (Figure 2) $(P<0.05)$. There was considerable variation in PCA morphine requirements among patients in both groups. There was no difference between the two groups for VAS pain scores (Figure 3). Patients in the clonidine group were significantly more sedated preoperatively (VAS sedation $=41$ vs 7$)(P<0.001)$ but no difference 


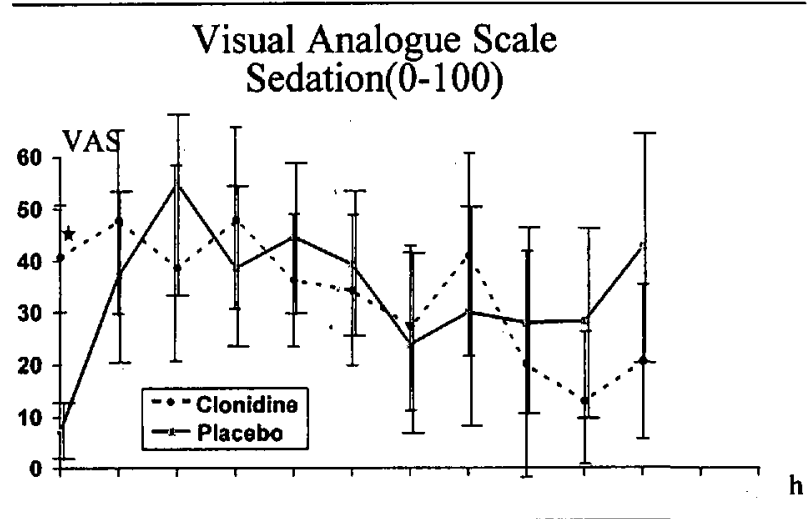

FIGURE 4 VAS for sedation in both groups every four hours postoperatively for $36 \mathrm{hr}$. Results are expressed as mean and SD. Patients in the clonidine group were more sedated preoperatively. $P<0.001$.

was found postoperatively (Figure 4). Patients who received clonidine had lower blood pressures throughout the period of study (Figure 5) $(P<0.0001)$ but this was not considered clinically serious.

Nausea and.vomiting were less frequent and fewer patients required anti-emetics after clonidine (Figure 6). However, there was no difference between clonidine and plabebo $(P=0.065)$ groups in the mean dose of dimenhydrinate required in those patients who' were given an antiemetic $(37.5 \pm 20.9 \mathrm{mg}$ vs $82.1 \pm 49.4 \mathrm{mg}$ respectively). There was no difference in supplemental oxygen use, time to ambulate $50 \mathrm{ft}$ with assistance, or the length of hospitalization between clonidine and placebo.

\section{Discussion}

Despite the wide range of individual variability in postoperative analgesia requirements our results indicated that oral clonidine reduces the cumulative intravenous PCA morphine requirements during the first $36 \mathrm{hr}$ after major knee surgery. The mean dose of morphine used in each $12 \mathrm{hr}$ period was also less after clonidine. Alpha adrenergic agonists have antinociceptive actions at spinal and supraspinal sites, ${ }^{13-15}$ and synergistic analgesic effects with opioids. ${ }^{16-18}$ However the alpha $_{2}$ adrenergic receptor is distinct to the mu and kappa opiate receptors associated with analgesia. Our results for oral clonidine are in agreement with previous studies that have demonstrated the potentiation of postoperative morphine analgesia by epidural, spinal or intravenous injection of clonidine. ${ }^{4-7}$

There was no difference in mean VAS pain score between the clonidine and placebo groups during the first 36 hr. Pain scores were highest in both groups on admission to the PACU but there was no correlation between morphine used and the VAS pain score. This is

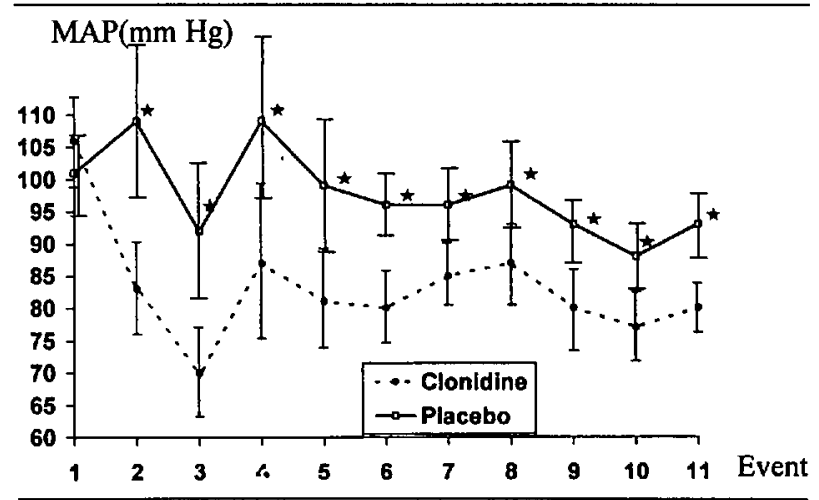

FIGURE 5 The numbered events are as follows: 1 = preop; 2 = preinduction; $3=1 \mathrm{~min}$ before intubation; $4=1 \mathrm{~min}$ after intubation; $5=3 \mathrm{~min}$ after intubation; $6=1 \mathrm{hr}$ after induction; $7=$ PACU; $8=8$ hr postop; $9=16 \mathrm{hr}$ postop; $10=24 \mathrm{hr}$ postop; $11=36 \mathrm{hr}$ postop. Results are expressed as mean and SD. Data were analyzed by ANOVA and subsequently by the unpaired Student $t$ test. $P<$ 0.0001 . $P$ values for group effect, time effect, interaction between group.time effect $<0.0001$.

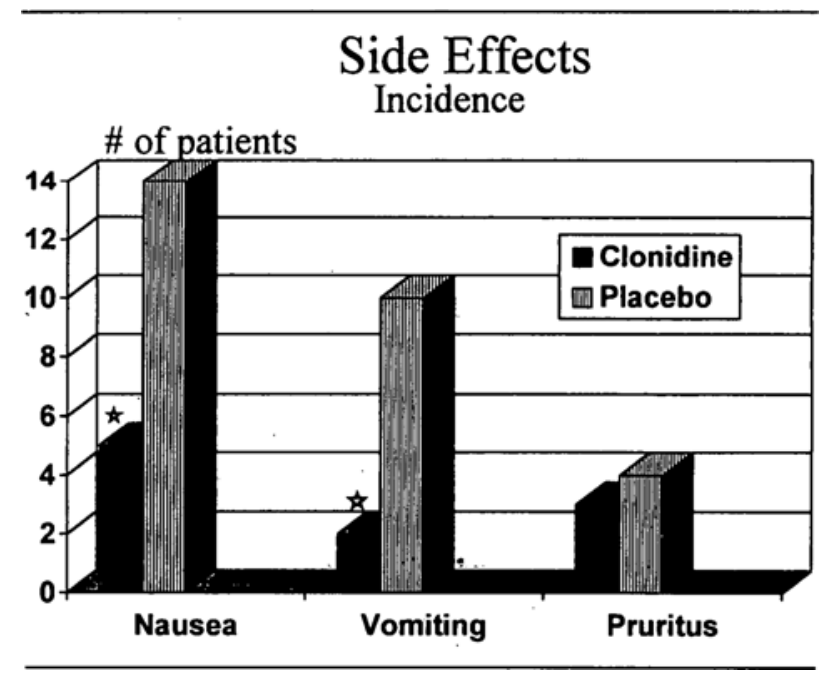

FIGURE 6 Number of patients who developed nausea (VAS $>25$ ), vomiting, or pruritus. $P P<0.01$.

perhaps not surprising given the inherent variability among patients of their perception of the severity of pain. It is possible that the use of continuous passive motion (CPM) may have resulted in augmentation of pain levels in the early hours after surgery to the extent that pain was not adequately controlled. Measurement of VAS pain scores was time related and did not differentiate whether VAS was recorded with the limb at rest or during passive movement due to lack of human resources.

We found no difference in postoperative sedation but patients who received clonidine had higher sedation scores preoperatively. This is in contrast to previous 
studies which demonstrated a sedative effect with clonidine after surgery. ${ }^{8,9}$ However one study demonstrated no sedative effect with clonidine after surgery. ${ }^{20}$ This discrepancy may be due to the fact that the previous studies $^{8,9,20}$ used a 3-5 point sedative score whereas VAS for sedation was used in our study. The VAS for sedation has been used in other studies. ${ }^{21-25}$ However the correlation between sedative score and VAS assessment of sedation is subject to further study. One patient in the placebo group was withdrawn from the study because of excessive sedation. The presence of postoperative sedation is fairly common after surgery performed under general anaesthesia, however in our patients this did not affect overall recovery since time to ambulation and length of hospitalization were similar.

Patients who received clonidine had reduced systolic blood pressure throughout the study. Eight patients in the clonidine group and two patients in the placebo group had a brief episode of hypotension at induction of anaesthesia which required treatment with intravenous ephedrine. There were no episodes of clinically significant postoperative hypotension in either group. We conclude that the dose of clonidine we used $\left(5 \mu \mathrm{g} \cdot \mathrm{kg}^{-1}\right)$ may have been excessive, especially in elderly patients in whom hypovolaemia, congestive heart failure, and bradycardia are more likely. Although none of our patients had clinical evidence of aortic stenosis, a degree of aortic inelasticity is to be expected in older patients. Hypotension and bradycardia are known central effects of clonidine mediated by decreased sympathetic outflow. However, in our patients the postoperative course was remarkably uneventful in terms of haemodynamic stability.

Although the incidence of postoperative nausea in our study was higher than reported in other published studies, 9,20 this was in most cases mild and did not require antiemetic therapy. It appears that clonidine may reduce the risk of postoperative nausea and vomiting after major knee surgery. There are two possible explanations for this observation. First, less PCA morphine was used by patients who received clonidine and thereby could have reduced the risk of opioid-induced nausea and vomiting. Second, clonidine may have antiemetic properties. There are two clinical studies to suggest this. ${ }^{26,27}$ Fetting et al. in their pilot study were able to demonstrate $50 \%$ reduction in the incidence of nausea and vomiting with the use of clonidine before chemotherapy on nine cancer patients who previously complained of chemotherapy related nausea and vomiting. Rosa-ESilva et al. reported substantial decreases in nausea, vomiting, and gastroparesis in six diabetics with diarrhoea. However the above two studies were not placebo controlled.
There are two possible mechanisms to explain this observation. First is the central mechanism of nausea and vomiting related to noradrenergic activity. A higher concentration of plasma 3 methoxy-4-hydroxyphenyl glycol (MHPG) was found in patients with nausea than without nausea during chemtherapy. ${ }^{28}$ In the study of Beleslin et al. intracerebroventricular injection of noradrenaline produced dose dependent and short lasting emesis. ${ }^{29}$ From the above observations it is postulated that vomiting is produced by noradrenaline and is mediated through alpha ${ }_{2}$ adrenoreceptors. These alpha adrenoreceptors appear to be located postsynaptically in the area postrema and transmit emetic impulses from the area postrema to the vomiging center of the brainstem reticular formation. ${ }^{29}$

It also apprears that clonidine, an alpha ${ }_{2}$ adrenoreceptor agonist decreases noradrenergic activity by binding to alpha $a_{2}$ presynaptic inhibitory adrenoreceptors in the locus coeruleus. ${ }^{30}$ The locus coeruleus provides most of the noradrenergic innervation to the cerebral, cerebellar cortices, the brain stem, and spinal cord lesions. ${ }^{31,32}$ Therefore, it seems reasonable to conclude that clonidine, by reducing the release of noradrenaline, produces an anitemetic effect.

However, there are many animal studies to contradict this. ${ }^{29,33,34,35}$ Van Dongen et al. in the non placebocontrolled animal study the intracerebral injection of clonidine near the locus coeruleus on 47 cats produced 10 episodes of vomiting. This was reproducible and was antagonized by alpha ${ }_{2}$ adrenoreceptor antagonist, yohimbine. ${ }^{33}$

It is difficult to explain the conflicting observations in the studies. ${ }^{26,27,29,33-35}$ There are several methological limitations which may have contributed to this discrepancy, such as non placebo-controlled, and small sample size. The role of different anatomical structures and/or physiological response to neurotransmitters between animals and humans, uncertainty of location of postsynaptic alpha ${ }_{2}$ adrenoreceptors in the central nervous system, potential different effects of presynaptic versus postsynaptic alpha $a_{2}$ adrenoreceptor stimulation, potential different effects of endogenous versus exogenous noradrenaline, the influence of neuronal loops and transynaptic regulatory mechanisms involving postsynaptic receptors may have complicated the results. ${ }^{36}$

Second, is the peripheral mechanism. Gastrointestinal distension stimulates vagal visceral afferents which in turn activate the vomiting centre and induce nausea and vomiting. ${ }^{37}$ Clonidine increases gastric emptying and gastrointestinal motility by increasing sympathetic outflow and decreasing parasympathetic outflow from the central nervous system. ${ }^{38}$ The antiemetic property of clonidine and the mechanism require further study. 
Other potentially beneficial effects of clonidine in the postoperative period include reduced shivering, ${ }^{19,39}$ less opioid-induced muscle rigidity, ${ }^{39}$ and less risk of increased intraocular pressure during intubation. ${ }^{40}$

In summary, perioperative oral clonidine has an opioid-sparing effect and may be a useful component of postoperative 'balanced analgesia'. It appears that clonidine may also reduce the incidence of postoperative nausea and vomiting. We recommend decreasing the dose of oral clonidine in patients over $65 \mathrm{yr}$ of age.

\section{Acknowledgements}

We would like to thank the nursing staff and anaesthetists at McMaster University teaching hospitals for their assistance and Dr. C. Goldsmith for his statistical advice.

\section{References}

1 Bloor BC, Flacke WE. Reduction in halothane anesthetic requirement by clonidine, an alpha-adrenergic agonist. Anesth Analg 1982; 61: 741-5.

2 Ghignone $M$, Quintin L, Duke PC, Kehler CH, Calvillo $O$. Effects of clonidine on narcotic requirements and hemodynamic response during induction of fentanyl anesthesia and endotracheal intubation. Anesthesiology 1986; 64: 36-42.

3 Richard MJ, Skues MA, Jarvis AP, Prys-Roberts C. Total i.v. anaesthesia with propofol and alfentanil: dose requirements for propofol and the effect of premedication with clonidine. Br J Anaesth 1990; 65: 157-63.

4 Bonnet $F$, Boico O, Rostaing S, Loriferne JF, Saada M. Clonidine-induced analgesia in postoperative patients: epidural vesus intramuscular administration. Anesthesiology 1990; 72: 423-7.

5 Eisenach JC, Lysak SZ, Viscomi CM. Epidural clonidine analgesia following surgery: phase I. Anesthesiology 1989; 71: 640-6.

6 Filos KS, Goudas LC, Patroni O, Polyzou V. Intrathecal clonidine as a sole analgesic for pain relief after cesarean section. Anesthesiology 1992; 77: 267-74.

7 Bernard J-M, Hommeril J-L, Passuti N, Pinaud M. Postoperative analgesia by intravenous clonidine. Anesthesiology 1991; 75: 577-82.

8 Segal IS, Jarvis DJ, Duncan SR, White PF, Maze M. Clinical efficacy of oral-transdermal clonidine combinations during the perioperative period. Anesthesiology 1991; 74: 220-5.

9 Benhamou D, Narchi P, Hamza J, Marx M-T, Peyrol T, Sembeil $F$. Addition of oral clonidine to postoperative patient-controlled analgesia with i.v. morphine. $\mathrm{Br} \mathrm{J}$ Anaesth 1994; 72: 537-40.

10 Davies DS, Wing $L M H$, Reid JL, Neill E, Tippett $P$, Dollery $C T$. Pharmacokinetics and concentration-effect relationships of intravenous and oral clonidine. Clin Pharmacol Ther 1977; 21:5 93-601.

11 Reid JL. The clinical pharmacology of clonidine and related central antihypertensive agents. $\mathrm{Br} J$ Clin Pharmacol 1981; 12: 295-302.

12 Forrest $J B$. Sympathetic mechanisms in postoperative pain (Editorial). Can J Anaesth 1992; 39: 523-7.

13 Maze $M$, Tranquilli $W$. Alpha ${ }_{2}$ adrenoceptor agonists: defining the role in clinical anesthesia. Anesthesiology 1991; 74: 581-605.

14 Yaksh TL, Reddy SVR. Studies in the primate on the analgesic effects associated with intrathecal actions of opiates, $\alpha$-adrenergic agonists and baclofen. Anesthesiology 1981; 54: 451-67.

15 Wang $Y-C$, Su C-F, Lin M-T. The site and the mode of analgesic actions exerted by clonidine in monkeys. Exp Neurol 1985; 90: 479-88.

16 Omote K, Kitahata LM, Collins JG, Nakatani $K$, Nakagawa $I$. Interaction between opiate subtype and alpha $_{2}$ adrenergic agonists in suppression of noxiously evoked activity of WDR neurons in the spinal dorsal horn. Anesthesiology 1991; 74: 737-43.

17 Spaulding TC, Fielding S, Venafro JJ, Lal H. Antinociceptive activity of clonidine and its potentiation of morphine analgesia. Eur J Pharmacol 1979; 58: 19-25.

18 Wilcox GL, Carlsson K-H, Jochim A, Jurna l. Mutual potentiation of antinociceptive effects of morphine and clonidine on motor and sensory responses in rat spinal cord. Brain Res 1987; 405: 84-93.

19 Flacke JW, Bloor BC, Flacke WE, et al. Reduced narcotic requirement by clonidine with improved hemodynamic and adrenergic stability in patients undergoing coronary bypass surgery. Anesthesiology 1987; 67: 11-9.

20 De Kock MF, Pichon G, Scholtes J-L. Intraoperative clonidine enhances postoperative morphine patient-controlled analgesia. Can J Anesth 1992; 39: 537-44.

21 Miguel R, Barlow I, Morrell M, Scharf J, Sanusi D, Fu E. A prospective, randomized, double-blind comparison of epidural and intravenous sufentanil infusions. Anesthesiology 1994; 81: 346-52.

22 Ghouri AF, Ramirez Ruiz MA, White PF. Effect of flumazenil on recovery after midazolam and propofol sedation. Anesthesiology 1994; 81: 333-9.

23 Robinson SL, Rowbotham DJ, Mushambi M. Electronic and disposable patient-controlled analgesia systems. A comparison of the Graseby and Baxter systems after major gynaecological surgery. Anaesthesia 1992; 47: 161-3.

24 Kontinen VK, Maunuksela E-L, Sarvela J. Premedication with sublingual triazolam compared with oral diazepam. Can J Anaesth 1993; 40: 829-34.

25 Franssen $C$, Hans $P$, Brichant JF, Noirot D, Lamy $M$. Comparison between alprazolam and hydroxyzine for oal premedication. Can J Anaesth 1993; 40: 13-7. 
26 Fetting JH, Sheidler VR, Stefanek ME, Enterline JP. Clonidine for anticipatory nausea and vomiting: a pilot study examining dose-toxicity relationships and potential for further study. Cancer Treatment Reports 1987; 71: 409-10.

27 Rosa-E-Silva L, Troncon LEA, Oliveira RB, Iazigi $N$, Gallo $L J r$, Foss MC. Treatment of diabetic gastroparesis with oral clonidine. Aliment Pharmacol Ther 1995; 9: 179-83.

28 Fetting JH, Stefaneck ME, Sheidler VR, Elsworth JD, Piantadosi S, Roth RH. Noradrenergic activity in anticipatory nausea. Psychosomatic Medicine 1992; 54: 641-7.

29 Beleslin $D B$, Strbac $M$. Nordrenaline-induced emesis. $\mathrm{Alpha}_{2}$ adrenoceptor mediation in the area postrema. Neuropharmacology 1987; 26: 1157-65.

30 Aghajanian $G$. Tolerance of locus coeruleus neurones to morphine and suppression of withdrawal response by clonidine. Nature 1978; 276: 186-8.

31 Redmond DE Jr, Huang YH. Current concepts. II. New evidence for a locus coeruleus-norepinephrine connection with anxiety. Life Sciences 1979; 25: 2149-62.

32 Charney DS, Redmond DE Jr. Neurobiological mechanisms in human anxiety. Evidence supporting central noradrenergic hyperactivity. Neuropharmacology 1983; 22: 1531-6.

33 Van Dongen PAM. Locus ceruleus region: effects on behavior of cholinergic, noradrenergic, and opiate drugs injected intracerebrally into freely moving cats. Exp Neurol 1980; 67: 52-78.

34 Jenkins $L C$, Lahay $D$. Central mechanisms of vomiting related to catecholamine response: anaesthetic implication. Can Anaesth Soc J 1971; 18: 434-41.

35 Lucot JB, Crampton GH. Xylazine emesis, yohimbine and motion sickness susceptibility in the cat. J Pharmacol Exp Ther 1986; 237: 450-5.

36 Langer SZ. Presynaptic regulation of the release of catecholamines. Pharmacol Rev 1981; 32: 337-62.

37 Andrews PLR. Physiology of nausea and vomiting. $\mathrm{Br} \mathrm{J}$ Anaesth 1992; 69: 2S-19S.

38 Flacke JW. Alpha2-adrenergic agonists in cardiovascular anesthesia. J Cardiothorac Vasc Anesth 1992; 6: 344-59.

39 Weinger $M B$, Segal IS, Maze $M$. Dexmedetomidine, acting through central alpha $a_{2}$ adrenoceptors, prevents opiateinduced muscle rigidity in the rat. Anesthesiology 1989 ; 71: 242-9.

40 Ghignone M, Noe C, Calvillo O, Quintin L. Anesthesia for ophthalmic surgery in the elderly: the effects of clonidine on intraocular pressure, perioperative hemodynamics, and anesthesia requirement. Anesthesiology 1988; 68: 707-16. 